\title{
FOCALIZANDO O EXERCÍCIO ADMINISTRATIVO NO CONJUNTO DE FUNÇÕES DO ENFERMEIRO
}

\author{
Maria Auxiliadora Trevisan* \\ Isabel Amelia Costa Mendes* \\ Neide Favaro** \\ Maria Suely Nogueira***
}

TREVISAN, M.A.; MENDES, I.A.C.; FÁVRO, N.; NOGUEIRA, M.S. Focalizando o exerć́cio administrativo no conjunto de funçōes do enfermeiro. Rev. Esc. Enf. USP, São Paulo, 23(1): -, abr. 1989.

Atualmente, no dimbito hospitalar, o enfermeiro nāo pode se furtar ao exerclcio da função administrativa, embora seja essa uma questão polêmica na enfermagem brasileira. Para focalizar o prohlema propöe-se neste estudo identificar o conjunto de funçöes do enfermeiro de unidade de internaçāo e detectar a distribuiçāo das funçōes administrativas, segundo suas caracterlsticas hurocräticas e nâo hurocráticas. Os dados foram coletados em quatro unidades de internaçäo, atranés de observaçâo intermitente do trabalho desempenhado por enfer. meiros em 1985. O conjunto de funçöes identificados foi o seguinte: Administrativas (62,5\%), Assistência do paciente (19,2\%), Ensino e Pesquisa (3,8\%). Delegaveis $(6,8 \%)$ e Particulares (7,6\%). As administrativas foram classificadas em Burocraticas e Não-Burocráticas, com uma distribuiçōo de $77 \%$ e $23 \%$, respectivamente. O estudo indica que a funçāo administrativa é uon dos elementos de definiçäo do perfil do enfermeiro, embora as autoras julguem que esse exercfio deva ser melhor orientado.

UNTTERMOS: Funções de enfermagem. Serviços de enfermagem hospitalar. Administração de serviços de enfermagem.

\section{INTRODUÇÃO}

Em pesquisas anteriores ${ }^{8.9}$ constatamos que o enfermeiro na unidade de internaçāo executava preponderantemente atividades administrativas e que estas ati-

- Enfermeira. Doutor em Enfermagem. Profeseor Assistente Doutor do Departamento de Enfermagem Geral e Eepecializada da EERP-USP.

- Enfermeira. Doutor em Sadde Poblica. Professor Assistente Doutor do Departamento de Enfermagem Geral e Espocializada da EERP-USP.

*** Auxiliar de Ensino do Departamento de Enfermagem Geral e Especializada da EERP-USP. 
vidades nāo representavam um meio de desenvolvimento e de alcance de metas preconizadas pela profissâo. Era e tem sido uma administraçāo que visa muito mais facilitar o serviço de outros profissionais na realização de suas tarefas na unidade de internaçāo do que concretizar os objetivos de seu próprio serviço. Nesse sentido, o enfermeiro tem se limitado a solucionar problemas para médicos, funcionários de laboratório, nutricionistas, atuando como elemento disciplinador de agentes variados num ambiente complexo.

Assim, o exencício administrativo pelo enfermeiro nunca foi compreendido e nem aceito pelos enfermeiros de ensino e também por muitos enfermeiros de serviço. Entendemos que esta falta de compreensão e aceitação se deva à evidente descaractetização da funçāo específica do enfermeiro como administrador, uma vez que os seus esforços estão sendo dirigidos para fins que subvalorizam o seu preparo - o enfermeiro tem ocupado um lugar subordinado e tem sido utilizado como sucedâneo de funçōes administrativas de outros ogāos ou disciplinas, possibilitando-lhe um distanciamento do desempenho de atividades inerentes à administração da assistência de enfermagem, às quais nāo se pode furtar.

$\mathrm{Na}$ vendade, o exercício da função administrativa pelo enfermeiro em nosso país é uma questão mesclada por muita polêmica. Esta polêmica se acompanha de uma falta de consenso sobre o conceito de função administrativa do enfermeiro, seja ela burocrática ou nāo burocrática.

Para focalizar o problema propōe-se neste estudo identificar o conjunto de funçōes do enfermeiro de unidade de internaçâo e detectar a distribuição das funçōes administrativas, segundo suas características burocráticas e nāo-burocráticas.

\section{METODOLOGIA}

Os dados foram coletados em um hospital-escola nas unidades de internaçāo Médica, Cirúrgica, Pediátrica e Ginecológica-Obstétrica, através de observaçāo intermitente, a cada quinze minutos, do trabalho desempenhado por enfermeiros.

Foram incluídos nos estudos os enfermeiros atuantes nas unidades citadas durante o período de coleta de dados, que compreendeu um conjunto de cinco dias consecutivos em 1985.

O início e o término do horário de observaçăo foi determinado pelo dia oficial de trabalho do enfermeiro. Assim, tendo a jornada de trabalho uma duração de seis horas e quarenta minutos, com início as 6:30 horas no plantāo matutino, a coleta de dados se estendeu ate às 12:30 horas. Nāo foram, portanto, considerados os quarenta minutos finais desta jornada pelo fato de abrangerem uma interface com o plantão seguinte e, desta forma, contar com a presença do enfermeiro da manhā e com o enfermeiro da tarde. 
O grupo de obeervadores foi constituf́do por alunos do Curso de Graduação em Enfermagem, treinados para cota finalidade.

Foram selocionados aqueles que já tinham conclúfdo o sexto semestre do referido curso e que tivessem demonstrado bom aproveitamento na disciplina de Administraçäo Aplicada a Enfermagem. Este critério foi utilizado considerando-se que os alunos que o preenchessem teriam subsídio para identificar o trabalho desenvolvido pelo enfermeiro.

O treinamento dos observadores abrangeu uma orientação inicial em que foi explicado o modo c o conteúdo da anotaçāo que seria feita sobre a função do enfermeiro, observado a cada quinze minutos. A anotação deveria restringir-se à descriçāo e registro do fato observado em formulário próprio, sem interferência no trabalho do enfermeiro observado.

Após a orientaçāo inicial e o esclarocimento de dúvidas que precederam a prática da observaçāo, passoutse a um treinamento individual de quatro horas sob a supervisāo e o controle das pesquisadoras que, em intervalos aleatórios, compararam a sua observação com aquela registrada pelo observador. A seguir ao treinamento, foi realizada nova reuniāo com o grupo de observadores; dúvidas foram esclarecidas, orientaçōes foram reforçadas e entāo passou-se à coleta de dados.

Foram acionados seis observadores, dos quais dois atuaram como volantes para substituição dos observadores fixos em horários de café e para averiguarem a localização do enfermeiro, quando ausente da unidade.

Contava-se com dois enfermeiros por dia, no período da manhã, em cada uma das quatro unidades estudadas. Ressalte-se que estes enfermeiros não estiveram sempre cacalados nos cinco dias de observação para o período da manhã; dar o total de 16 enfermeiros envolvidos neste trabalho.

\section{RESULTADOS: ANÁLISE E DISCUSSĀO}

Embora nosso objetivo estivesse restrito à análise das funções administrativas, nāo poderíamos deixar de relacions-las a contexto do qual elas foram extrafdas.

Assim, a Tabela 1 exibe a distribuição das funçōes desempenhadas pelos enfermeinos, nos cinco dias de observação, segundo as unidades estudadas. Comparando essas funçōes, fica ressaltada a preponderáncia das funçōes administrativas sobre as demais. Ao lado daquela preponderáncia, a Tabela 1 sugere a existéncia de uma rendéncia de pouco exencício de funçôes de colaboração ao ensino e à pesquisa, uma flutuaçào nas funçóes delegáveis e particulares entre as unidades $e$ sugere ainda que o percentual módio das funçōes de assisténcia ao paciente, nas unidades observadas, nāo atingiu $20 \%$. 


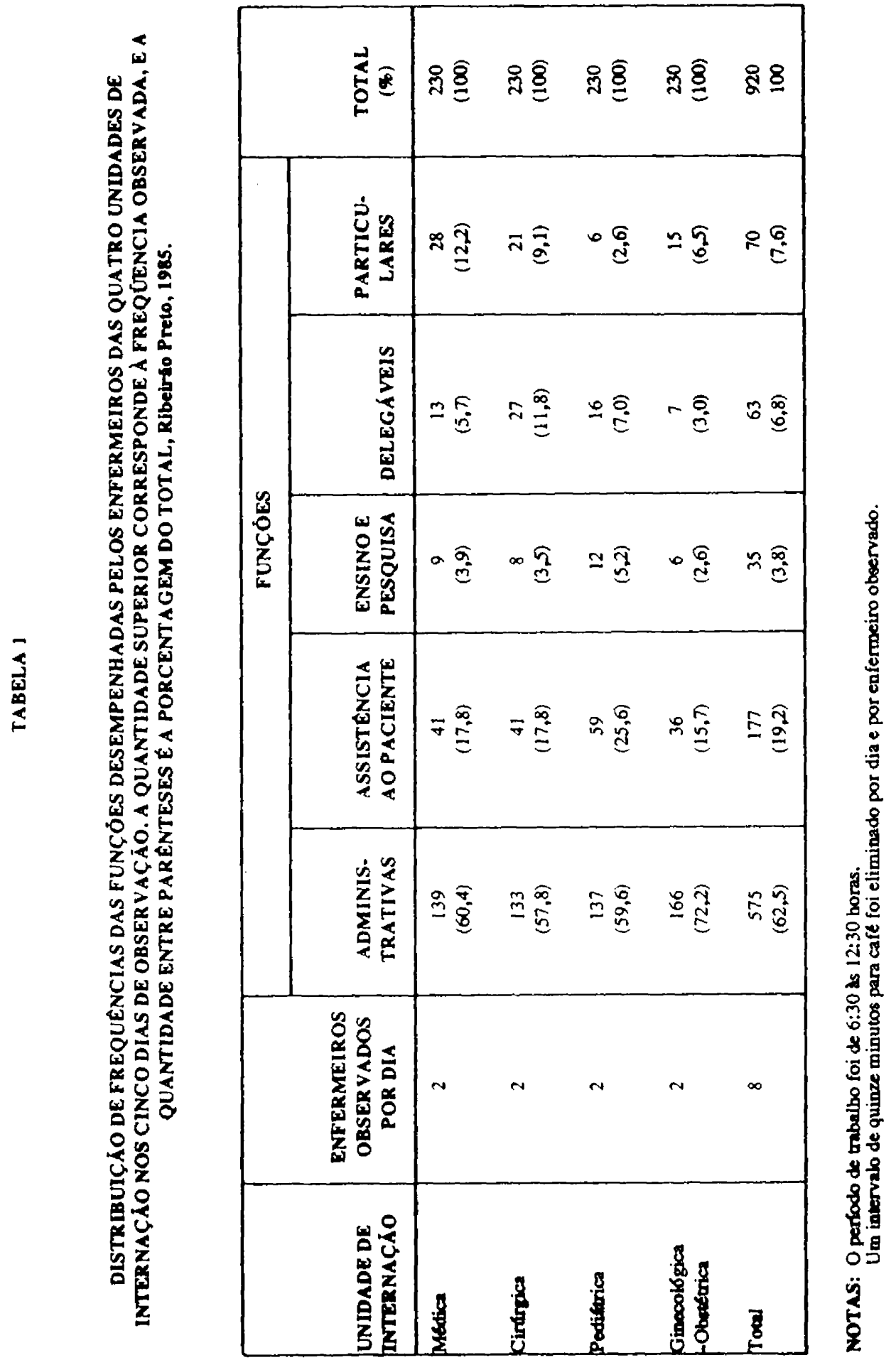


As funçöes administrativas foram analisadas e classificadas a luz dos conceitos de funçăo administrativa burocrática e nāo-burocrática. Consideramos como funçōes de assistência a paciente aquelas desempenhadas diretamente com e para o paciente; como funçōes de colaboraçāo ao ensino e à pesquisa identificamos as executadas com alunos ou relacionadas a investigaçōes científicas; como funçōes delegáveis aquelas cujo desempenho, no nosso entender, sub-utilizam o preparo do enfermeiro, como por exemplo, lavar material, preencher pedidos de exames, etc; c como particulares foram classificadas as funçōes desligadas do serviço.

Estudando a variaçāo do percentual das referidas funçōes por unidade de internação, observa-se na Tabela 1 que:

a) as funçōes particulares mostraram maior frequência nas Unidades Médica e Cirúrgica; b) a Unidade Cirúrgica apresenta o maior percentual de funçōes delegáveis; c) com exceçāo da Unidade Pediátrica, o menor percentual está relacionado ao desempenho de funções de colaboração ao ensino e à pesquisa; d) as funçöes de assistência ao paciente alcançaram maior percentual na Unidade Pediátrica, seguida por um percentual idêntico nas Unidades MÉdica e Cirúrgica; e) a Unidade Ginecológica-Obstétrica apresenta o maior percentual de funçöes administrativas, enquanto que nas demais Unidades o percentual destas funçōes também foi bastante considerável e preponderante.

Teoricamente tem sido apregoado que o enfermeiro deve dedicar-se à assistência direta aos pacientes, e fazer dela o seu objeto de trabalho. Entretanto, nossos resultados demonstram que, com exceçāo dos enfermeiros da Unidade de Intemaçāo Pediátrica que totalizaram $25,6 \%$ nessas funçōes (veja Tabela 1), os demais enfermeiros observados nāo chegam a dedicar $20 \%$ de seu tempo às funçōes de assistência $\infty$ paciente. Este índice sugere que parece persistir uma concepção entre alguns enfermeinos da instituição estudada de que essa funçāo pode ser delegada, como já havíamos constatado através de entrevistas ${ }^{10}$.

Em relaçáo às funçōes de ensino e pesquisa podemos constatar que os enfermeiros observados estâo limitados a um papel de apoio a esses assuntos, que seria a fase inicial da hierarquia dos papéis de pesquisa sintetizados por BOWIEl. 2. Ao total e entre as cinco funçōes, esta recebe menos dedicação por parte dos enfermeiros. Entretanto, pelos achados de LOPES5, todos os enfermeiros que participaram de seu estudo referiram reconhecer a necessidade de participar de pesquisa de enfermagem.

Confirmando nossa assertiva em trabalho"11 sobre essa funçâo, é desejável uma soma de esforços entre os profissionais de ensino e de serviço no sentido de capacitar os ultimos para o exercício gradativo de papéis técnico e consumidor de pesquisa e finalmente de investigador.

Os desvios encntrados em relação às funçōes particulares e delegáveis merecem estudo mais aprofundado para detecção e determinaçăo de correçōes, principalmente nas Unidades Médica e Cirúrgica. 


\section{ANÁLISE DAS FUNÇŌES ADMINISTRATTVAS BUROCRÁTICAS}

Como mencionamos, as funçōes administrativas foram subdivididas em burocráticas e näo-burocráticas.

A função administrativa burocrática envolve a utilizaçāo do conhecimento tócnico-especializado sobre administraçāo e o seu exercício contribui para o alcance dos objetivos da organização. Ela é norteada pela imparcialidade e objetividade.

Uma organizaçāo burocrática abrange funçōes claramente definidas e vinculadas aos fins da organização, onde cargos e status hierarquizados integram-se e implicam deveres e direitos estabelecidos e regidos por normas. Neste tipo de estrutura "a conduta administrativa, de modo geral, realiza-se dentro do limite de normas pré-estabelecidas pela organização"'.

Assim sendo, a funçăo administrativa burocrática é um tipo de comportamento impessoal que é orientado detalhadamente por normas, rotinas e objetivos traçados pela organização. $\mathrm{O}$ comportamento do administrador segue-se ao compromisso para com a organizaçāo.

A classificação operacional dessas funçōes exercidas pelos enfermeiros foi fundamentada em estudos de ETZIONI ${ }^{4}$, MOTTA \& PEREIRA ${ }^{7}$ e WEBER ${ }^{12}$.

Deste modo, a Tabela 2 indica a distribuição de freqüencia das funções administrativas burocráticas desempenhadas pelos enfermeiros, nos cinco dias de observação, de acordo com as unidades estudadas. Observa-se nesta tabela que o tipo de funçāo burocrática mais desenvolvido pelos enfermeiros observados nas unidades de Internação Médica e Pediátrica é Orientar funcionários sobre normas, rotinas e atribuiçōes. A funçāo Verificar prontuários, exames, escalas de cirurgia obteve maior freqüência na Unidade Ginecológica-Obstétrica seguida pela Unidade Cirúrgica e Pediátrica. Implementar ordens médicas foi a funçāo burocrática mais exencida pelos enfermeiros da Unidade Cinúrgica, apesar de apresentar menor frequência se comparada à Unidade Ginecológica-Obstétrica.

Focalizando-se os totais das quatro Unidades na Tabela 2, podemos observar que, por ordem de frequiência, as funçöes Orientar funcionários sobre normas, rotinas e atribuiçōes, Verificar prontuários, exames, escalas de cirurgia, Receber, passar ou dirigir passagem de plantāo e Implementar ordens médicas foram as mais desenvolvidas. Podemos perceber que os tipos de funçōes burocráticas mais contemplados pelos enfermeiros correspondem às espectativas da organização hospitalar e às espectativas médicas. Entretanto, o tipo de função que recebeu menos atenção dos enfermeiros emana de expectativas do próprio serviço de enfermagem: Supervisionar e avaliar o trabalho do pessoal auxiliar. 


\section{ANÁLISE DAS FUNÇÕES ADMINISTRATIVAS NĀO-BUROCRÁTICAS}

A função adninistrativa não-burocrática também contribui para o alcance dos objetivos da organização, mas depende da utilização do preparo e competência profissional do enfermeiro, visando a qualidade do trabalho executado.

Portanto, difere da burocrática: $1^{-9}$ ) não é regida detalhadamente por normas, $2^{\circ}$ ) depende mais da competência do indivíduo, 39) deixa lugar para a criatividade, 4)! deixa espaço para um estilo pessoal e 59) enquanto a funçāo burocrática é comandada pelo compromisso à organização, a não-burocrática é mais orientada pelo compromisso com a profissão.

TABE.A.A 2

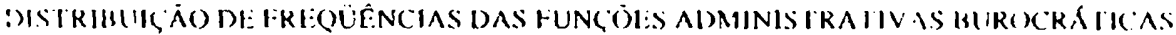
DESSEMIIENHADAS PI:LOS ENFERATEIROS, NOS CINCO DIAS DI: OHSIERVAC ( LASSIFICADAS SEGUUNDO A UNIDASEE DE INTIERNACÃO ESIUUDADA, Ribeirăo Preto, 1985.

\begin{tabular}{|c|c|c|c|c|c|}
\hline \multirow[b]{2}{*}{ Funçăo Burocráticu } & \multicolumn{5}{|c|}{ UNIDADE DE INIEKNACÁO } \\
\hline & Médica & Cirfirgica & Pediátrica & $\begin{array}{l}\text { Cinernlogicy- } \\
\text { Obstetrica }\end{array}$ & Tot:ul \\
\hline $\begin{array}{l}\text { Elaborar, nunter e coordeniu } \\
\text { escala de funcionários }\end{array}$ & 14 & 3 & 2 & 7 & 26 \\
\hline Implenientar ordens médicus & 17 & 22 & 3 & 2.3 & 65 \\
\hline $\begin{array}{l}\text { Orientar funcionários sobre } \\
\text { nurmas, rutinas e atribuiçñen }\end{array}$ & 22 & 14 & 33 & 17 & $x_{t}$ \\
\hline $\begin{array}{l}\text { Solicitar providencias e } \\
\text { responder a questōes nomativias } \\
\text { de outros departamentos }\end{array}$ & 10 & 15 & 8 & 6 & 39 \\
\hline $\begin{array}{l}\text { Verificar prontuários, exumes, } \\
\text { escalas de cirurgia }\end{array}$ & 12 & $1 x$ & 17 & 30 & 77 \\
\hline $\begin{array}{l}\text { Receber, passar ou dirigir } \\
\text { passagem de plantho }\end{array}$ & 13 & 17 & 19 & 17 & 66 \\
\hline $\begin{array}{l}\text { Trocar in formaçoes sobre } \\
\text { problemas da unidade com } \\
\text { superiores. }\end{array}$ & 11 & 8 & 11 & 6 & 36 \\
\hline $\begin{array}{l}\text { Fazer provisăo de re:ursos } \\
\text { humanos e materiais }\end{array}$ & 10 & 11 & 9 & 5 & 35 \\
\hline $\begin{array}{l}\text { Supervisionar e avalias o } \\
\text { trabalho do pessoal auxiliar }\end{array}$ & 3 & 3 & 4 & 3 & 13 \\
\hline TOTAL & 112 & 111 & 106 & 114 & 443 \\
\hline
\end{tabular}

A Tabela 3 engloba as funçōes administrativas nāo-burocráticas, extraŕdas do estudo de campo, bem como suas frequiências. Convém esclarecer que o fato de relacionarmos apenas as seis encontradas nāo significa que as funçōes administrati- 
vas não-burocráticas, no nosso entender, se restrinjam a elas.

Pode-se verificar na Tabela 3 que das seis funçōes nāo-burocráticas observadas, a de freqüência preponderante é a de tipo orientar paciente e familia sobre exames, cirurgias, cuidados pós-alta, retornos e estado do paciente. Seguem-se a ela as funçōes Informar médico sobre providências tomadas quanto a exames solicitados e Fazer visitas aos pacientes. A de menor freqüência é a do tipo Pedir informação ou receber solicitação do médico sobre cuidados, seguida pela função Participar de reunião de grupo de estudos de educação continuada que ocorreu exclusivamente na Unidade de Internação Pedí́tnca e representa a iniciativa de um grupo de enfermeiros interessados em estudar alternativas para a melhoria da assistência.

TABEL,A 3

DISTRIBUIÇĀO DE FREQÜÊNCIAS DAS FUNÇŌES ADMINISTRATIVAS NĀO-BUROCRATICAS DESEMPENHADAS PELOS ENIERMEIROS, NOS CINCO DIAS DE OBSERVAC $\tilde{O}($, CLASSIFICADAS SEGUNUO A UNIDADE DE INTERNAC C̄O ESTUDAIAA.

Ribeirăo Preto, 1985.

\begin{tabular}{|c|c|c|c|c|c|}
\hline \multirow[b]{2}{*}{ Funçăo Não-Burucrátlica } & \multicolumn{4}{|c|}{ UNIDADE DE INTERNAÇĀO } & \multirow[b]{2}{*}{ Total } \\
\hline & Medicy & Cirúrgica & Pediátrica & $\begin{array}{c}\text { Ginecologica- } \\
\text { Ohstétrica }\end{array}$ & \\
\hline $\begin{array}{l}\text { Participar de reunião de } \\
\text { grupo de estudos de educaç̧ăo } \\
\text { continuada }\end{array}$ & 0 & 0 & 11 & 0 & 11 \\
\hline $\begin{array}{l}\text { Transmitir e/ou receber } \\
\text { informax̧oes } \$ \text { /da equipe de } \\
\text { enfermagem sobre assistencia }\end{array}$ & 5 & $s$ & 0 & 4 & 14 \\
\hline $\begin{array}{l}\text { Orientar paciente e famflia } \\
\text { sobre exames, cirurgias, } \\
\text { cuidados pos-alta, retomo } \\
\text { e estado do paciente }\end{array}$ & 6 & 6 & 10 & 17 & 39 \\
\hline $\begin{array}{l}\text { Informar medico sobre } \\
\text { providencias tomadas quanto a } \\
\text { exames solicitados }\end{array}$ & $x$ & 5 & 6 & 12 & 31 \\
\hline $\begin{array}{l}\text { Pedir informaçăo ou receber } \\
\text { solicitaç\$s do medico sobre } \\
\text { cuidados }\end{array}$ & 1 & 4 & 1 & 1 & 7 \\
\hline Fayer visita ans pacientes & 7 & 2 & 3 & 18 & 30 \\
\hline TOTAL & 27 & 22 & 31 & 52 & 132 \\
\hline
\end{tabular}

\section{ANÁLISE DO NÍVEL DE BUROCRATIZAÇÃO DAS FUNÇÕES}

O confronto das Tabelas 2 e 3 mostra a preponderânca das funçōes burocráticas sobre as nāo-burocráticas. Esta preponderência foi formalmente analisada definindo um índice de burocratização, e estudando as variações desse índice ao variar a unidade de internação. 
Define-se este f́ndice para cada unidade mediante o quociente

$$
I=\frac{B}{\mathbf{B}+\mathbf{N B}}
$$

do número $\mathrm{B}$ de funçōes burocráticas pela quantidade total de funções burocráticas e não-burocráticas (NB) realizadas na unidade de internação.

Os valores deste indice ( 0,80 na Unidade Médica; 0,83 na Unidade Cinúrgica; 0,77 na Unidade Pediátrica; 0,69 na Unidade Ginecológica-Obstétrica) nāo mostraram variaçōes significativas entre unidades de internação. A porcentagem média destes valores sugere que as funçōes administrativas burocráticas perfazem $77 \%$ do total das funçōes administrativas.

\section{CONSIDERAÇŌES FINAIS}

Os resultados encontrados mostrando $77 \%$ de exercício em funçōes administrativas burocráticas e $23 \%$ em não burocráticas indicam uma tendência para a rotinizaçāo e impessoalidade e, portanto, vinculaçāo mais acentuada a normas préestabelecidas.

$O$ enfermeiro tem se dedicado sobremaneira às funções esperadas por parte de diversos profissionais da área hospitalar e tem apresentado uma tendência a negligênciar suas próprias funçōes profissionais - executa funçōes seguindo diretrizes que the são impostas por outros órgãos ou serviços.

Entretanto, entendemos que este profissional deve assumir sua inserçāo no modelo burocrático mas imprimindo uma nova forma de atuação. Acreditamos numa perspectiva alternativa de reconciliação entre a orientação profissional e a burocrática, dada a interdependência entre elas. Porisso é preciso sensibilizar o enfermeiro para uma postura positiva em relação a sua funçăo administrativa mesmo porque pela sanção da Lei no 7.498 , de 25/06/1986, que dispōe sobre a regulamentação do exercício da enfermagem ${ }^{3}$, e de acordo com seu artigo 110 Enfermeiro exerce todas as atividades de enfermagem, cabendo-lhe:

I - privativamente:

a) direçāo do órgâo de enfermagem integrante da estrutura básica da instituiçāo de saúde, pública e privada, e chefia de serviço e de unidade de enfermagem;

b) organizaçāo e direção dos serviços de enfermagem e de suas atividades tócnicas e auxiliares nas empresas prestadoras desses serviços;

c) planejamento, organizaçāo, coordenaçāo, execução e avaliação dos serviços de assistência de enfermagem; ... ${ }^{3}$

TREVISAN, M.A.; MENDES, I.A.C.; FÁ VERO, N.; NOGUEIRA, M.S.

Focalizing the administrative exercise in the set of nurse's functions. Rev.

Esc. Enf. USP, São Paulo, 23(1):-, Apr. 1989. 


\section{SUMMARY}

Within the hospital contex, the nurse cannot avoid the administrative function, even though this is a controversial issue in Brazilian nursing. To focus on the problem, in the present study we set out to identify the set of functions of nurses working on the admission floors and to determine the distribution of administrative functions according to their bureaucratic and non-bureaucratic characteristics. The data mere collected at four admission units by intermittent observation of work performed by nurses in 1985. The following set of functions were identified: administration (62,5\%), patient assistance $(19,2 \%)$, teaching and research $(3,8 \%)$, functions that could be delegated to others $(6,8 \%)$ and personal (7,6\%). The administrative functions were classified into bureaucratic and nonbureaucratic with a respective distribution of $77 \%$ and $23 \%$. The study indicates that the administrative function is one of the elements defining the nurse's profile, even though the authors believe that this function should be better oriented.

UNITERMS: Nursing, functions. Nursing service, hospital. Nursing administration service.

\section{REFERÊNCIAS BIBLIOGRÁFICAS}

1. BOWIE, R.B. Research responsabilities of the clinical nurse. AORN J., Denver, 31(2): 23841, 1980.

2. - The nurse researcher's roles and responsabilites. AORN J., Denver, 31(4):609-11, 1980.

3. BRASIL. Leis, decretos, etc. Lei 7498 de 25 jun. 1986. Diário Ofiedal, Brastia, 26 jun.

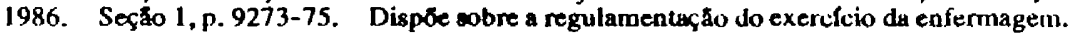

3. ETZIONI, A. Orgenizaçбes modernas. Sto Paulo, Pioneira, 1967. 189p.

5. LOPES, C.M. A produçふo dos enfermeiros assistenciais em relaçă a pesquisa em enfermagem, em um munictpio paulista. Ribeirso Preto, 1983. 133p. (Dissercaçto de mestrado- Escola de Enfermagem de Ribeirto Preto da USP).

6. MERTON, R.K. Estrutura burocrática e personalidade. In: CAMPOS, E. Sochalogía da burocracia. Rio de Janeiro, 7.ahar, 1966. cap. ,p.

7. MOTTA, F.C.P. \& PEREIRA, L.C.B. Introduçăo o organizaçắo burocrática. 2.ed. Sto Paulo, Brasiliense, 1981.p.

8. TREVISAN, M.A. Estudo das atividades dos enfermeiros-chefes de unidade de internaçáo de um hospital-escola. Ribeirao Preto, 1978, 117 p. (Dissertaço de mestrado - Escola de Enfermagem de Ribeirlo Preto da USP).

9. TREVISAN, M.A.; MENDES, I.A.C.; FÁVERO, N, Atividades administrativas desempenhadas por enfermeiros-chefes. Rev. Paul. Hosp., Sro Paulo, 28(7): 204-10, 1980.

10. TREVISAN, M.A.; MENDES, I.A.C.; FÁVERO, N.; COSTA, M.A.T.R. Acerca da dedicaçlo do enfermeiro-chefe is atividades de assistencia direta ao peciente. Rev. Paul. Hosp., Săo Paulo, 28(8): 227-33, 1980.

11. TREVISAN, M.A.; MENDES, I.A.C.; FÁVERO, N; NACARATO, C.F. A respeito da colaboraçho do enfermeiro de servico as acividades de ensiro e pesquisa. Enf. Atual Rio de Janeiro, 4(23): 10-6, 1982.

12. WEBER, M. The essentials of bureaucratic organization: an ideal - type construction. In: MERTON, R.K.; GRAY, A.P.; HOCKEY, B.; SELVIN, H.C. Reader in bureaucracy. Glencoe, The Frle Press, 1952. p. 